\title{
Status constraint and lifestyle transition: a latent class analysis of health-related lifestyles among different social strata in China
}

\author{
Fuqin Wang
}

Correspondence: wfq0927@163.com Department of Sociology, Tongji University, No. 1239, Siping Road Yangpu District, Shanghai, China

\begin{abstract}
The present study uses data from the Chinese General Social Survey (CGSS) to develop a multidimensional measure for the healthiness of Chinese citizens' lifestyles. A latent class analysis reveals variety in Chinese people's lifestyles. Three categories are identified: the healthy, the mixed, and the risky. People with higher socio-economic status (SES) are polarized between the healthy and the risky lifestyles, while those with lower SES tend to have a more mixed lifestyle. Generally speaking, Chinese people's lifestyles are in constant change. Located in an advantageous social-structural position, members of the upper strata manage to choose the lifestyle beneficial to their health. At the same time, however, they are influenced by western lifestyles. Members of the lower strata are more constrained by social-structural status.
\end{abstract}

Keywords: socio-economic status, healthy lifestyle, lifestyle transition, latent class analysis

\section{Introduction}

The first 60 years of the twentieth century were dubbed "the age of medicine." Largescale vaccination essentially eliminated or suppressed the incidence and death rates of infectious diseases. Currently, developed societies are entering "the post-medicine era," as incurable, chronic and non-infectious diseases gradually replace curable, acute and infectious diseases to be the major challenge in the world of medicine. Nowadays, one's health is increasingly influenced by social and environmental factors (Cockerham, 2014). According to the World Health Organization, chronic diseases have become the primary reason for death and disability within the world population (WHO, 2005). The increase in chronic disease incidence and deaths has become a global public health issue. Research shows that in modern societies, health is primarily related to certain lifestyles. Health-risky behaviors, such as smoking, the over-consumption of alcohol, a lack of physical activity, and an unhealthy diet are thought to be major causes of chronic diseases. Such lifestyles, especially if they persist for a long time, have cumulative negative effects on one's health.

Existing research on developed countries has discovered a rather stable trend-the members of the lower social strata have less healthy lifestyles. The healthy lifestyle

(C) The Author(s). 2019 Open Access This article is distributed under the terms of the Creative Commons Attribution 4.0 International License (http://creativecommons.org/licenses/by/4.0/), which permits unrestricted use, distribution, and reproduction in any medium, provided you give appropriate credit to the original author(s) and the source, provide a link to the Creative Commons license, and indicate if changes were made. 
reproduction theory maintains that members of the lower social strata are at a disadvantage when it comes to matters like stress management, old-age benefits, risk awareness, efficacy, agency, assisted health-related behavior, class and class distinction, neighborhood opportunity, social capital, and so on. Contrary to the research on developed countries, however, research on China has found that members of the higher strata are more likely to behave in a health-risky way than members of the lower strata, a phenomenon not well-explained by the socio-economic status (SES) perspective. On the one hand, the lifestyle transition theory argues that as China has gone through social transition, people's lifestyles have changed rapidly and have been influenced by western lifestyles. Members of the higher social strata and the urban population have been the first to be affected by the unhealthy elements of the western lifestyle (such as the consumption of calorie-dense, processed, and fried foods). On the other hand, the continued prominence of the Chinese tobacco and alcohol culture has also contributed to the comparatively less healthy lifestyles of the higher strata compared to the lower (Kim et al. 2004). Less scholarly attention has been paid to investigating the characteristics of Chinese citizens' health-related lifestyles against the backdrop of rapid lifestyle change and the official promotion of healthy lifestyles, nor has much attention been paid to examining if the health-SES relationship is converging with that of the developed world.

The present study analyzes data from the Chinese General Social Survey (CGSS) and attempts to address issues in the measurement of healthy lifestyles through research design. The study assumes that people with the same or similar lifestyles exhibit similar health behaviors. As such, it uses health-related lifestyles as the latent variable and concrete health-related behaviors as manifest variables to construct latent class models for measuring people's health-related lifestyles. Thus, it attempts to clarify the relationship between SES and health-related lifestyles.

\section{Low SES and risky health behaviors}

A rich body of research has found a negative correlation between SES and risky healthrelated behavior (Christensen and Carpiano, 2014; Morris et al. 2016; Skalamera and Hummer, 2016). The lower a person's SES, the higher the likelihood of risky healthrelated behavior and the less healthy his or her lifestyle is likely to be. Members of the higher social strata are unlikely to behave in health-risky ways, and their lifestyles are usually healthy or preventive (Roshchina, 2016). Multiple theoretical explanations have been proposed for the correlation between SES and health-related lifestyles (Pampel et al. 2010). This paper summarizes them into two major approaches-an individualist and a structuralist-based on their arguments about the productive mechanism of health-related behaviors ${ }^{1}$.

\section{Individualist explanations}

The individualist approach focuses on the psychology, cognition, efficacy, and economic condition of members of lower SES. The theories and arguments included in this

\footnotetext{
${ }^{1}$ Pampel et al. (2010) summarize nine explanations for the negative correlation between SES and health behavior. But one argument of the latent trait theory maintains that statistical correlations are a type of pseudo-correlation, rather than a causal relation. This argument is not supported by empirical evidence, and therefore it is not included in this literature review.
} 
approach are relative deprivation and stress, old-age benefits, risk cognition, efficacy, agency, and assisted health behavior, among others.

The deprivation and stress explanation derives from the press process theory. It maintains that members of lower SES are in a relative state of status deprivation and are more likely than members of higher SES to suffer from life stress or negative events (Pearlin and Menaghan, 1981) such as unemployment, financial loss, marriage breakdown, and discrimination. Risky health behaviors such as smoking, drinking, and overeating are their coping mechanisms to adapt and resist this stress (Gilbert and Zemore, 2016). Members of the upper social strata are less likely to confront these pressures or negative events, and they are more resourceful in dealing with life stress.

The old-age benefit explanation is based on cost and benefit principles. It argues that because members of lower strata expect to receive fewer benefits from healthy behavior (that can lead to longer life), they are less willing to invest in healthy behavior. On the contrary, members of the upper strata care about their own health and behave in healthy ways (such as through exercise, healthy eating, getting enough sleep, and so on) in the hope of prolonging their lives, enjoying life and continue their work, so as to consolidate their SES (Biddle and Hamermesh, 1990).

The risk cognition argument holds that one's health-related behavior reflects beliefs about health and risk awareness about the disease. People who believe that healthy lifestyles can promote health are more likely to behave in healthy ways. A risk awareness for disease and a negative diagnosis can have a positive effect on one's health-related behavior (Ferrer and Klein, 2015). A Chinese study has found that people take in significantly less fat after being diagnosed with high blood pressure, and the effect is more prevalent in high-income groups (Zhao et al. 2012).

According to the efficacy and agency argument, education increases not only one's edge in status attainment, but also one's efficacy, agency, capability in obtaining and processing information, and problem-solving ability, thereby strengthening one's control over one's life. This helps with the internalization of healthy behavior into a healthy lifestyle (Mirowsky and Ross, 1998). Therefore, keeping a healthy lifestyle, which requires perseverance and overcoming difficulties, is more likely for those with a higher SES (especially higher levels of education). Agency is often more important than knowledge about health risks (Mirowsky and Ross, 2007).

According to the assisted health-related behavior argument, although there is no direct relationship between economic ability and healthy behavior ${ }^{2}$, access to certain health services, such as consultation, fitness clubs, boot camps, smoking or alcohol support groups, healthy grocery stores, and specialized exercise gear providers require sufficient economic ability (Cutler and Lleras-Muney, 2010). For members of lower SES, the economic bar for assisted health-related behaviors is too high.

To summarize, for the individualist approach, the mechanism linking SES to healthy lifestyles includes social pressure, expectations, cognition, awareness, efficacy, agency, and assistance. These provide concrete explanations for members of the lower social strata to engage in risky health-related behaviors. This approach focuses, however, on individual-level symptoms and overlooks how SES as a structural factor constrains

\footnotetext{
${ }^{2}$ Not all healthy behaviors require additional expenditure. For example, jogging, a healthy aerobic exercise, does not entail any cost. On the contrary, risky health behaviors like smoking and drinking are costly.
} 
individual behavior on a higher level. It also fails to consider how lifestyles mark boundaries between different status groups and reflect group (class) stratification.

\section{Structuralist explanations}

The structuralist approach focuses on class/stratification, residential segregation, and differentiation in social capital and networks, resulting from people's different social locations, as causes of the variation in health-related behavior. Theories in this camp include class distinction, neighborhood opportunity, and social capital.

The class distinction theory originates from Weber's theory of status groups, which are distinguished based on social reputation and lifestyle. Weber assumes that the lifestyles of different status groups are necessarily distinguishable from each other (Weber [1946] 2004). Building on Weber, Bourdieu (1984) describes people's daily activities (which include but are not limited to healthy behavior) as a kind of social practice. Under certain field structures, Bourdieu argues, people choose certain lifestyles based on their habitus. In turn, lifestyles also reflect people's locations in a certain field structure. Lifestyle functions as a distinction for social classes.

The neighborhood opportunity explanation argues that different kinds of neighborhoods provide different amounts of opportunities for their residents to engage in a healthy lifestyle. Low-income neighborhoods lack infrastructure (such as fitness facilities, parks, leisure centers) and businesses. Residents have to travel far to large grocery stores with healthy food options, as close-by convenience stores sell only fast food. Their health-related lifestyle choices are thus constrained (Powell et al. 2006).

The social capital theory holds that healthy lifestyles are a mechanism by which social capital influences people's health. Social networks and social support help promote healthy behavior and suppress risky behavior (Kaljee \& Chen, 2011). Social capital influences one's health-related behavior in two ways. First, members in a network exchange health-related information, pass on healthy behaviors, make health-related decisions and supervise each other in their practice (Lindström, 2008). Second, social cohesiveness is higher in high-SES neighborhoods. Members are more likely to form cooperative networks based on mutual trust and mutual benefits, encouraging healthy behavior (Kawachi et al. 2008).

The structuralist approach emphasizes the constraint SES puts on people's healthrelated behavior or lifestyle choices. A more abstract perspective than the individualist approach, the structuralist approach overlooks micro-level factors that can also be influential. Generally speaking, the two approaches explain the SES-lifestyle correlation from different angles, and they are complementary to each other. Cockerham (2010), following Weber's theorization of status groups, defines a healthy lifestyle as a series of health-related modes for collective behavior in which people make life choices between options provided by their own opportunities. He emphasizes the dual influence on healthy lifestyles asserted by individual agency and structure. Previous research is lacking in the following theoretical and methodological issues. First, theoretically presumed differences produce conceptual differences between healthy behavior and healthy lifestyles. Early healthy behavior or lifestyle research stresses individual choice in healthy behavior, and it hence usually uses one single behavior as the core dependent variable. It was not until the most recent two decades that the concept of health- 
related lifestyles was employed. One single health-related behavior cannot reflect the complex effect that all behaviors have on health, nor can it reflect the social inequalities in health-related behaviors. When analyzing the relationship between SES and one single health-related behavior, different results often exhibit a certain degree of variation, or even contradiction. When using comprehensive measurements, however, results become quite significant (Friestad and Klepp, 2006). This means we should adopt a more complex perspective in health studies and health practices that takes into consideration multi-faceted health-related behaviors (Morris et al. 2016). Second, many studies focus only on risky health behaviors such as smoking, drinking, and unhealthy diet, but they overlook the influence of health-promoting behaviors such as exercise and regular physical examination (Abel et al. 2000). Third, many studies that use multidimensional measurements either integrate lifestyle variables only in elementary ways (adding the scores of all indicators; an example is Kim et al. 2004), or use cluster analysis (an example is Chan and Leung, 2015). Either approach is able to eliminate general correlations among behavior indicators. The constructed variable does not truly reflect whether people's lifestyles essentially differ. These issues need to be reconsidered in future research.

\section{Changes in Chinese citizens' lifestyles and class differences}

\section{Lifestyle changes and nutritional transition}

Under the influence of industrialization, urbanization, population aging, changes in the ecological environment and changes in lifestyle, the incidence and death rate of chronic diseases have been increasing in China. High blood pressure, diabetes, cerebrovascular diseases, and malignant tumors are all on the rise. Chronic diseases have become the major threat to the health of Chinese citizens (National Health and Family Planning Commission, 2015).

The rapid spread of chronic diseases in China is closely related to lifestyle changes. More than forty years after the Reform, Chinese citizens' lifestyles have seen considerable transformations ( $\mathrm{Li}, 2012$ ). In terms of material lives, housing conditions, living environments, and sanitary conditions, all improved significantly. In terms of diet, the nutrition transition theory's argument that developing and low-income countries are experiencing a lifestyle "westernization" is most clearly observed in China (Popkin, 2003). Since the Reform, urban residents have seen considerable changes in fiber intake and fat intake. The Chinese population has gradually transitioned from undernutrition to overnutrition, and from a stage of receding famine to a stage of degenerative disease (Zhai et al. 2010). Moreover, dietary structures have also experienced significant changes, with the consumption of snacks gradually increasing and cooking techniques changing from steaming and boiling to frying (Wang et al. 2008). In terms of forms of labor, the nutrition transition theory notes a decrease in labor intensity across industries and occupations due to the substitution of physical labor with modern automated machinery. People are now sitting for long times and lack the necessary physical exercise (Popkin, 2003). In terms of tobacco and alcohol consumption, $52.9 \%$ of Chinese men smoked in 2010, a much higher rate than the global average of $32 \%$; only $2.4 \%$ of Chinese women smoked in 2010, however, much lower than the global average of $8 \%$. Even though the proportion of men who smoke has been decreasing since 1990, the 
number has stagnated at a high level (State Tobacco Monopoly Administration, 2013). Adult men also take in much more alcohol and have a higher rate of pernicious alcohol consumption compared to adult women (China Alcoholic Drinks Association, 2015). Smoking, overdrinking, lack of physical activities, and a high-sodium and high-fat diet are the main behavioral risk factors for chronic diseases such as being overweight, obesity, high blood pressure, cardiovascular and cerebrovascular diseases, and diabetes in China.

\section{Class differences in healthy lifestyles}

Although the correlation between low SES and risky behavior has passed empirical tests in most countries, it is not supported by a number of research in China. Wang and his colleagues have found that high-income Chinese families and urban residents purchase more snacks and fried foods than low-income families and rural residents. That is, the lifestyles of high-SES groups have gradually moved to the unhealthy end (Wang et al. 2008). Chan and other's studies of SES and lifestyle in Hong Kong have also discovered that people with medium to high levels of education and who are employed lead a less healthy lifestyle than those with low levels of education and who are unemployed (Chan and Leung, 2015). These findings are opposite to the trends found in developed countries. In addition, Kim and his colleagues compare the health-related lifestyles (diet, exercise, smoking, and drinking) of Chinese and Americans with various SES and found that the two countries have opposite trends. Contrary to trends in the USA, Chinese people privileged in terms of SES often have a less healthy lifestyle. The authors attribute this difference to the disparity in socioeconomic development of the two countries, and they maintain that lifestyles change with economic development, and the mode of this change differs for different social classes (Kim et al. 2004). After China's Reform, government-controlled food allocation was abandoned, and people were able to purchase food as they wished on the market. Purchase and consumption modes started transitioning. Members of the upper class and urban residents were the first to be influenced by western lifestyles, but certain behaviors in these lifestyles differed between China and the US. For example, in the US (as in other developed western countries), processed foods have low costs and are therefore mainly purchased by the working class or groups with low SES. On the contrary, such foods are often expensive in China, so only the upper class or groups with high SES can afford them. They are even seen as a symbol of wealth. In terms of exercise, the use of modern office gear and machines deprives members of the upper class physical exercise during their work and increases the time they spend in front of an electronic screen (Kim et al. 2004). Kim and colleagues summarize these findings into the lifestyle transition theory to explain, to an extent, why developing countries see a higher incidence of nutrition-related non-infectious diseases in their upper-class populations. The lifestyle transition theory and the nutrition transition theory both point out the western influence on the lifestyles of developing countries, as well as the influence of economic development. Strictly speaking, the lifestyle transition theory has not gone beyond the framework of the nutrition transition theory, but the former focuses more on explaining lifestyle differences among different social classes in developing countries. 
At present, China's economy is still growing rapidly. Its comprehensive national power has reached that of a mid-level developed country. The economic and education levels of Chinese citizens keep increasing, and their health awareness keeps growing. At the same time, great official efforts have been put toward controlling smoking and promoting healthy lifestyles. How will the lifestyles of different SES groups change? Will the trend seen in developed countries ensue? Or has China still not transcended the plateau in the nutrition transition for developing countries? This study analyzes and tests these questions.

\section{Hypotheses}

The status constraint hypothesis

Cockerham, combining Weber's theory of status groups and Bourdieu's theory of social practice, proposes the theory of healthy lifestyle reproduction (Cockerham, 2010). This theory postulates that social structures (class structures, age, gender, race/ethnicity, collectivity, life conditions, etc.) constrain individuals' opportunities, and socialization and personal experience influence individuals' life choices. Under the mutual influence of opportunities and life choices, individuals form behavioral tendencies (habitus) regarding healthy lifestyles and forms of life behavior. These behavioral modes construct healthy lifestyles and the practices of these lifestyles in turn influence individuals' behavioral tendencies (habitus). From the sociological perspective, the healthy lifestyle theory integrates the individualist and the structuralist approaches in their explanations of the stable correlation between SES and health behavior (lifestyle). Previous research in developed western countries provides empirical support for this theoretical model.

Since the Reform, the Chinese social structure has experienced fast transformation, enlarging the gap between social classes. Although scholars have reached different conclusions about the intensity of social stratification in China, they agree that the resources and interests of different social classes have differentiated and diversified. Members of the upper class enjoy considerable advantages in educational attainment, income distribution, wealth, etc. Social stratification has caused significant class differences in consumption behaviors, living spaces, and physical exercise. Members of the upper class focus more on life quality and consumption (Zhu, 2013), they live in better communities where housing prices are higher (Liu and Li, 2005), and they frequently participate in physical exercise (Wang, 2012). According to the healthy lifestyle reproduction theory, SES is an important structural variable constraining people's choices regarding health-related lifestyles in both the individual agency dimension and the structural dimension. Under the current social stratification in China, this paper proposes the status constraining hypothesis for health-related lifestyles:

Hypothesis 1: Members of low SES are more likely to be constrained by their socialstructural location and make less healthy choices in health-related lifestyles; on the contrary, members of high SES are freer to choose their lifestyle and make healthier choices.

\section{The lifestyle transition hypothesis}

In the lifestyle transition theory proposed by Kim and colleagues, lifestyle changes come with national economic development, and different SES groups exhibit different 
modes of transition (Kim et al. 2004). As a developing country, China, in the process of economic marketization, has seen significant changes in its people's nutrition and diet given the influence of western lifestyles (Popkin, 2003). In terms of diet, members of the upper social class, having higher economic ability, consume more expensive but unhealthy foods. Physical exercise is also influenced by modern forms of work-members of the upper class rely more on computers and consequently move less. At the same time, tobacco and alcohol cultures are still prominent in China. As seen from data on tobacco and alcohol consumption in the recent two decades, consumption has not noticeably decreased, even in the face of steady price increases ${ }^{3}$. Although the data used in Kim and colleagues' study is rather old and the study has some research design issues, studies based on recent survey data (including studies in Hong Kong) have also revealed the unhealthy lifestyles of the Chinese upper class (Wang et al. 2008). The argument of the lifestyle transition theory is not negated. As such, I propose the lifestyle transition hypothesis.

Hypothesis 2: The higher a person's SES is, the less healthy their lifestyle is. On the contrary, those with lower SES have a healthier lifestyle.

The status constraint hypothesis and the lifestyle transition hypothesis seem like two opposite faces of one hypothesis. But they have different starting points and different theoretical mechanisms. The status constraint hypothesis is based on the healthy lifestyle reproduction theory. It emphasizes how social-structural locations differentiate the resources people of different SES have in their disposal, and this in turn constrains their opportunities. The lifestyle transition hypothesis is based on the nutrition transition theory. It reflects the argument that in fast-developing countries (especially China), people's lifestyles are widely influenced by "westernization." A transition from undernutrition to overnutrition and degenerative diseases is underway. While all social classes are affected by this process, the upper class might be experiencing a bigger influence. The healthy lifestyle theory is built on and tested by empirical studies in developed western countries, while the lifestyle transition theory is built on the empirical reality in developing countries. In short, the two theories do not come from the same context. As such, they yield different predictions about the SES-healthy lifestyle relationship in China.

\section{Research design}

Variable measurement

The dependent variable

Healthy lifestyles are measured as a latent class by health-related behavior. Actual health-related behaviors include smoking, drinking, physical exercise, rest and relaxation, as well as regular physical examination. Each is measured in the following way.

(1) Smoking: the respondent's smoking frequency. Five categories are included:

"never," "several times a year," "several times a month," "several times a week," and "every day," coded from 1 to 5 , respectively.

${ }^{3}$ Please refer to the CPI of tobacco and alcohol under "price indices" in the Chinese Statistical Yearbook. 
(2) Drinking: the respondent's drinking frequency. Similar to smoking, this variable also has five categories: "never," "several times a year," "several times a month," "several times a week," and "every day," coded from 1 to 5 , respectively.

(3) Physical exercise: how often the respondent engages in physical exercise (that is over 20 minutes in length and can make them sweat or increase their breathing rate). It has the same five categories: "never," "several times a year," "several times a month," "several times a week," and "every day," coded from 1 to 5, respectively.

(4) Rest and relaxation: how the respondent schedules their leisure time. Four categories are included: "rarely rest," "sometimes rest," "rest regularly," and "always resting," coded from 1 to 4 , respectively.

(5) Regular physical examination: how often the respondent has taken a physical exam in the last three years. This variable has three categories: "never," "irregularly," and "regularly," coded from 1 to 3, respectively.

Descriptive statistics of the five behavioral variables and the construction of the latent class variable are included in the first part of the data analysis section.

\section{Independent variables}

SES is measured by the respondent's education, occupation, and income.

(1) Education: the highest level of education attained by the respondent. This variable has four categories: "primary school or below," "middle school," "high school or equivalent," and "vocational college and above," coded from 1 to 4, respectively.

(2) Occupation: the respondent's current occupation (or the last occupation before retirement). Using the EGP11 occupational class framework, we integrate respondents' occupations into six categories: "managerial/professional skilled employee," "ordinary nonphysical employee," "small business owner/individual businessman," "foreman/skilled worker," "unskilled physical laborer," and "agricultural laborer," coded from 1 to 6, respectively.

(3) Income: the natural log of the respondent's gross annual income in the last year before the survey.

\section{Controlled variables}

In previous research on health-related behavior in other countries, gender and age are basic controlled variables.

(1) Gender: male is coded as 1 and female is coded as 0 .

(2) Age: the numerical difference between the year of the survey and the respondent's year of birth. Building on existing empirical studies, this research also controls the square of the age. But to account for the scale effect, the square of the age is divided by 100 .

(3) Birth cohort. all respondents are divided into two birth cohorts: before and after 1978. Those born in and before 1977 are coded as 0, and those born in and after 1978 are coded as 1 . 
(4) Urban residency: respondents were coded as 1 if they lived in a city or a town and were coded as 0 if they lived in a rural area. This is because of the considerable difference in the level of development between cities and the countryside.

\section{Data and method}

This study uses data from the 2010 "China General Social Survey" (CGSS 2010). This survey is jointly conducted by the Center for Survey and Statistics at Renmin University and other academic institutions throughout the country. It adopts a layered design and a multi-stage PPS sampling strategy. The general population (over 18 years old) of 31 provinces (excluding Hong Kong, Macau, and Taiwan) was sampled ${ }^{4}$. In total, 11,783 samples were collected. Due to the research design, however, the part of the survey that is about health (part M) was only conducted on respondents born in January, April, June, and August. The effective sample, therefore, contains only 3866 respondents. In the analysis, samples with missing values for any variable were deleted. The final sample used for the analysis contains 2895 respondents. The sample is weighted in the final statistical models. Table 1 shows the basic information of the sample.

This paper uses latent class models and multivariate logistic regression models.

The latent class model estimates and explains the correlation between manifest variables through the latent class variable. As such, local independence is established (Qiu, 2008). The five manifest variables included in this study are smoking, drinking, physical exercise, rest, and relaxation, as well as a regular physical examination. They are denoted by A, B, C, D, and E, respectively. The latent class analysis model, then, can be written as:

$$
\pi_{i j k l m}^{A B C D E}=\sum_{t}^{T} \pi_{t}^{X} \pi_{i t}^{\bar{A} X} \pi_{j t}^{\bar{B} X} \pi_{k t}^{\bar{C} X} \pi_{l t}^{\bar{D} X} \pi_{m t}^{\bar{E} X}
$$

in which $i, j, k, l$, and $m$ are the values of their corresponding manifest variables, and $\pi_{i j k l m}^{A B C D E}$ denotes the joint distribution probability of manifested variables, as estimated by the latent class model. $\pi_{t}^{X}$ is the probability that the observation belongs to a certain type $t$ of the latent class variable $X$, where $t=1,2, \ldots$ T. $\pi_{i t}^{\bar{A} X}$ is the probability that an observation belonging to the $t$ th latent class takes the value of $i$ in the behavioral variable A. The same logic applies to the rest.

Since the latent lifestyle classes are categorical variables, the SES-lifestyle correlation is often predicted and analyzed with multivariate logistic regression. This is a common model used in categorical data analysis, so this paper will not go into its details.

\section{Data analysis}

\section{Health-related behaviors and the lifestyles of Chinese citizens}

This paper measures the health-related lifestyles of Chinese urban and rural residents with five behavioral variables: smoking, drinking, physical exercise, rest and relaxation,

\footnotetext{
${ }^{4}$ For detailed descriptions on sampling, please refer to "Sampling plan for the Second Wave of the China General Social Survey (2010-2019)." This document can be downloaded from either the RUC Center for Survey and Statistics website (http://www.chinagss.org/) or the Chinese National Survey Data Archive website (http://cnsda.org/).
} 
Table 1 Descriptive Statistics of the Sample of the Health Section (section M) in CGSS2010

\begin{tabular}{|c|c|c|c|c|c|}
\hline \multirow[t]{2}{*}{ Categorical variables } & \multirow[t]{2}{*}{ Values } & \multicolumn{2}{|l|}{$\begin{array}{l}\text { Unweighted } \\
(N=2895)\end{array}$} & \multicolumn{2}{|l|}{$\begin{array}{l}\text { Weighted } \\
(N=2930)\end{array}$} \\
\hline & & Sample size & Percentage & Sample size & Percentage \\
\hline \multirow[t]{2}{*}{ Gender } & Male & 1559 & 53.9 & 1672 & 42.9 \\
\hline & Female & 1336 & 46.1 & 1258 & 57.1 \\
\hline \multirow[t]{2}{*}{ Residency } & Rural & 1226 & 42.3 & 1395 & 47.6 \\
\hline & Urban & 1669 & 57.7 & 1535 & 52.4 \\
\hline \multirow[t]{2}{*}{ Birth cohort } & In or before 1977 & 2402 & 83.0 & 2409 & 82.2 \\
\hline & In or after 1978 & 493 & 17.0 & 521 & 17.8 \\
\hline \multirow[t]{4}{*}{ Educational attainment } & Primary school or below & 1011 & 34.9 & 1072 & 36.6 \\
\hline & Middle school & 933 & 32.2 & 981 & 33.5 \\
\hline & High school or equivalent & 515 & 17.8 & 499 & 17.0 \\
\hline & $\begin{array}{l}\text { Vocational college or } \\
\text { above }\end{array}$ & 436 & 15.1 & 377 & 12.9 \\
\hline \multirow[t]{6}{*}{ Occupational status } & $\begin{array}{l}\text { Managerial/professional } \\
\text { employee }\end{array}$ & 396 & 13.7 & 357 & 12.2 \\
\hline & $\begin{array}{l}\text { Ordinary non-physical } \\
\text { worker }\end{array}$ & 352 & 12.2 & 310 & 10.6 \\
\hline & $\begin{array}{l}\text { Small business owner/ } \\
\text { individual businessman }\end{array}$ & 280 & 9.7 & 300 & 10.2 \\
\hline & Foreman/skilled worker & 291 & 10.1 & 276 & 9.4 \\
\hline & Unskilled physical worker & 452 & 15.6 & 450 & 15.4 \\
\hline & Agricultural laborer & 1124 & 38.8 & 1236 & 42.2 \\
\hline Continuous variables & Range & Mean & $\begin{array}{l}\text { Standard } \\
\text { deviation }\end{array}$ & Mean & $\begin{array}{l}\text { Standard } \\
\text { deviation }\end{array}$ \\
\hline Age & {$[18,96]$} & 47.3 & 14.8 & 46.4 & 14.4 \\
\hline Annual income (RMB) & {$[50,6000000]$} & 22108.5 & 118221.9 & 21250.9 & 112438.8 \\
\hline $\begin{array}{l}\text { Natural log of annual } \\
\text { income }\end{array}$ & $(3.91,15.61)$ & 9.2 & 1.2 & 9.2 & 1.2 \\
\hline
\end{tabular}

and regular physical examination. As shown in Table 2 (the descriptive statistics column), in general, Chinese people's health-related behaviors appear to be multidimensional, in which every healthy behavior takes up a certain percentage and the distributions of the behaviors differ from each other. Smoking exhibits a two-tailed concentration, as most respondents either never smoke or smoke every day. Those who smoke every day take up $31.0 \%$ of the sample. For drinking, $58.1 \%$ of all respondents never drink, whereas the rest distribute more or less equally-at about 10\%-among "several times a year," "several times a month," "several times a week," and "every day." The distribution of physical exercise is similar to that of smoking, with $53.5 \%$ of respondents answering "never" and $17.2 \%$ answering "every day." The percentage of respondents who exercise several times a week is higher than that of respondents who exercise several times a month, and both are higher than that of respondents who exercise several times a year. As for relaxation, although the first two categories claim more respondents than do the last two, those who "rest regularly" or are "always resting" take up $54.8 \%$ of the sample. For physical examination, $43.2 \%$ of the sample never take physical exams, whereas $37.0 \%$ take them irregularly and $19.8 \%$ take them regularly.

Because of the significant difference in the distribution among behavioral variables, this study uses a latent class analysis to better study how people combine these 
Table 2 Descriptive statistics of health behaviors and the probabilities and conditional probabilities of lifestyle latent classes, $N=3827$

\begin{tabular}{|c|c|c|c|c|c|c|}
\hline \multirow[t]{2}{*}{ Lifestyle indicators } & \multirow[t]{2}{*}{ Measurement } & \multicolumn{2}{|c|}{ Descriptive statistics } & \multicolumn{3}{|c|}{ Conditional probability } \\
\hline & & Sample size & Percentage & Class 1 & Class 2 & Class 3 \\
\hline \multirow[t]{5}{*}{ Smoking } & Never & 1890 & 65.3 & .8461 & .8800 & .0202 \\
\hline & Several times a year & 18 & 6 & .0006 & .0114 & .0142 \\
\hline & Several times a month & 17 & 6 & .0036 & .0043 & .0174 \\
\hline & Several times a week & 73 & 2.5 & .0116 & .0001 & .0895 \\
\hline & Every day & 897 & 31.0 & .1381 & .1042 & .8587 \\
\hline \multirow[t]{5}{*}{ Drinking } & Never & 1681 & 58.1 & .8273 & .6645 & .0124 \\
\hline & Several times a year & 292 & 10.1 & .0536 & .1631 & .1342 \\
\hline & Several times a month & 356 & 12.3 & .0393 & .1197 & .2760 \\
\hline & Several times a week & 261 & 9.0 & .0268 & .0422 & .2882 \\
\hline & Every day & 305 & 10.5 & .0530 & .0105 & .2893 \\
\hline \multirow[t]{5}{*}{ Physical exercise } & Never & 1548 & 53.5 & .7715 & .0589 & .5401 \\
\hline & Several times a year & 255 & 8.8 & .0499 & .1643 & .1253 \\
\hline & Several times a month & 220 & 7.6 & .0164 & .2032 & .0752 \\
\hline & Several times a week & 373 & 12.9 & .0355 & .3154 & .1225 \\
\hline & Every day & 499 & 17.2 & .1267 & .2583 & .1369 \\
\hline \multirow[t]{4}{*}{ Rest and relaxation } & Rarely & 491 & 17.0 & .2002 & .0924 & .1884 \\
\hline & Sometimes & 818 & 28.3 & .2723 & .3105 & .2648 \\
\hline & Regularly & 1196 & 41.3 & .3672 & .5015 & .4261 \\
\hline & Always resting & 390 & 13.5 & .1603 & .0956 & .1207 \\
\hline \multirow[t]{3}{*}{ Regular physical examination } & Never & 1251 & 43.2 & .5574 & .1259 & .5082 \\
\hline & Irregularly & 1070 & 37.0 & .3497 & .4819 & .3346 \\
\hline & Regularly & 574 & 19.8 & .0929 & .3921 & .1571 \\
\hline Latent class probability & -— & -— & - - & .5261 & .2768 & .1971 \\
\hline
\end{tabular}

Note: the sample size is 3827 , which includes all effective responses in the original sample (3866 observations). To maximize the use of the effective sample, weighted original sample is used in descriptive analysis of lifestyle and in constructing latent class models later in this paper

behaviors. To discover whether there is a latent class variable with explanatory power behind the five behavioral variables, this study uses the software Latent Gold 4.5 to apply multiple fittings to the data. Table 3 shows the results. Among the five latent class models constructed, the $-2 \mathrm{LL}\left(G^{2}\right)$ value of model 3 has a probability of 1.00 , indicating that latent variables with three categories best fit the data and have the smallest BIC. Further analysis also finds that a model with three latent classes has significant explanatory power for every indicator. Thus, such a model is ideal for estimating people's latent lifestyle classes.

Table 3 Explorative fitting of latent class analysis models, $N=3827$

\begin{tabular}{llllllll}
\hline Model & $X^{2}$ & $G^{2}$ & $\mathrm{df}$ & $p$ & Npar & AlC & BIC \\
\hline Model 1: 1 class & 4696.25 & 2752.01 & 1482 & $4.3 \mathrm{e}-79$ & 17 & 42978.05 & 43084.30 \\
Model 2: 2 classes & 3001.20 & 1772.47 & 1464 & $4.3 \mathrm{e}-8$ & 35 & 42034.50 & 42253.25 \\
Model 3: 3 classes & 1962.45 & 1245.04 & 1446 & 1.00 & 53 & 41543.08 & 41874.32 \\
Model 4: 4 classes & 1718.37 & 1109.98 & 1428 & 1.00 & 71 & 41444.01 & 41887.75 \\
Model 5: 5 classes & 1465.70 & 1005.46 & 1410 & 1.00 & 89 & 41375.50 & 41931.73 \\
\hline
\end{tabular}


After deciding that three classes are ideal, the probability of each latent class and the conditional probability of the class of each indicator are calculated. Results are shown in Table 2 (the conditional probability column). We can infer the characteristic of each latent class based on its conditional probability on each manifest variable.

Class 1 has the highest conditional probabilities on options like "never smoke," "never drink," "never exercise," "rarely rest," and "never take physical exams." It includes both healthy behaviors like not smoking and not drinking, and risky behaviors like not exercising, rarely resting and not taking physical exams. It is a relatively complex class. I term this lifestyle "the mixed lifestyle." Similar to class 1 , class 2 contains the "never smoke" and "never drink" options. Unlike class 1, though, class 2 also has positive conditional probabilities on physical exercise, rest, and regular physical exams. In general, class 2 exhibits characteristics of a healthy life on all five variables. Therefore, I call class 2 "the healthy lifestyle." Class 3 has the highest conditional probabilities on the "smoke every day" and "drink every day" options. At the same time, like class 1, class 3 also has high conditional probabilities on options like "never exercise," "rarely rest," and "never take physical exams." All of these behaviors increase an individual's risk of having diseases, and so class 3 is termed the "the risky lifestyle." The latent class probabilities of the mixed lifestyle, the healthy lifestyle, and the risky lifestyle are, respectively, $52.61 \%, 27.68 \%$, and $19.71 \%$. This speaks to the multidimensional characteristic of Chinese citizens' lifestyles with each kind of lifestyle taking up a certain percentage.

Strictly speaking, both mixed and risky lifestyles are unhealthy, but each has a different negative influence on people's health. The mixed lifestyle is more likely to produce nutrition-related chronic diseases, whereas the risky lifestyle is more likely to produce respiratory and cardiovascular diseases. From the distribution of the three kinds of lifestyles among the total population, there is still much to improve in Chinese people's health-related lifestyles.

\section{The relationship between socio-economic status and health-related lifestyles}

In order to analyze the influence of SES on people's health-related lifestyles and to test the status constraint hypothesis and the lifestyle transition analysis, this study uses the posterior probability estimated by the latent class model (model 3) to divide the sample into three categories, and it uses a multivariate logistic regression model to estimate the influence of the controlled variables and SES on health-related lifestyles. The results are reported in Table 4.

As shown, significant correlations exist between each control variable and healthrelated lifestyle, as well as between SES and health-related lifestyles. Take the coefficients of the healthy/risky type as an example. Men, middle-aged people, and the rural population have less healthy lifestyles (the risky lifestyle). Specifically speaking, compared to men, women are 65 times $\left(=\exp ^{4.181}\right)$ more likely to have a healthy lifestyle. This is consistent with research on other countries. The magnitude of this advantage, however, is related to the large consumption of tobacco and alcohol by Chinese men. The age-lifestyle relationship exhibits a U-shaped curve, with teenagers and elders living a healthier life and middle-aged people more likely to live an unhealthy life. This challenges Chen and Leung's (2015) conclusion that young people lead an less healthy lifestyle. Urban residents are 1.575 times more $\left(=\exp ^{0.454}\right)$ likely than rural 
Table 4 Multivariate logistic regression of the SES-lifestyle relation

\begin{tabular}{|c|c|c|c|c|c|c|}
\hline \multirow[t]{2}{*}{ Variable } & \multicolumn{2}{|c|}{ Healthy/risky } & \multicolumn{2}{|l|}{ Mixed/risky } & \multicolumn{2}{|c|}{ Healthy/mixed } \\
\hline & $b$ & $\operatorname{Exp}(b)$ & $b$ & $\operatorname{Exp}(b)$ & $b$ & $\operatorname{Exp}(b)$ \\
\hline Constant & $3.153^{* * *}$ & & $7.249^{* * *}$ & & $-4.096^{* * *}$ & \\
\hline Gender & $-4.181^{* * *}$ & .015 & $-4.032^{* * *}$ & .018 & -.149 & 0.861 \\
\hline Age & $-.106^{* * *}$ & .899 & $-.105^{* * *}$ & .901 & -.002 & 0.998 \\
\hline $\mathrm{Age}^{\wedge} 2$ & $.131^{* * *}$ & 1.140 & $.123^{* * *}$ & 1.131 & .008 & 1.008 \\
\hline Residency & $.454^{* *}$ & 1.575 & -.191 & .826 & $.645^{* * *}$ & 1.907 \\
\hline \multicolumn{7}{|l|}{ Education } \\
\hline College and above & $1.251^{* * *}$ & 3.495 & $-.667^{* *}$ & .513 & $1.918^{* * *}$ & 6.808 \\
\hline High school and equivalent & $.562^{* *}$ & 1.755 & $-.506^{* *}$ & .603 & $1.068^{* * *}$ & 2.910 \\
\hline Middle school & $.634^{* * *}$ & 1.884 & -.083 & .921 & $.716^{* * *}$ & 2.047 \\
\hline \multicolumn{7}{|l|}{ Occupational status } \\
\hline Managerial/professional employee & $.697^{* *}$ & 2.007 & .218 & 1.244 & $.478^{*}$ & 1.613 \\
\hline Ordinary non-physical worker & .433 & 1.541 & -.127 & .880 & $.560^{* *}$ & 1.751 \\
\hline $\begin{array}{l}\text { Small business owner/individual } \\
\text { businessman }\end{array}$ & .438 & 1.549 & $.453^{*}$ & 1.573 & -.015 & .985 \\
\hline Foreman/skilled worker & $.670^{* *}$ & 1.953 & .347 & 1.414 & .323 & 1.381 \\
\hline Unskilled physical worker & $.419^{*}$ & 1.52 & $-.330^{*}$ & .719 & $.749^{* * *}$ & 2.114 \\
\hline Natural log of annual income & .080 & 1.083 & $-.128^{*}$ & .879 & $.208^{* * *}$ & 1.232 \\
\hline$-2 \mathrm{LL}$ & 4535.279 & & & & & \\
\hline Degree of freedom & 26 & & & & & \\
\hline Pseudo $R^{2}$ (Cox and Snell) & .393 & & & & & \\
\hline Prob $>\mathrm{Chi}^{2}$ & .000 & & & & & \\
\hline
\end{tabular}

Note: ${ }^{*} p<0.05,{ }^{* *} p<0.01,{ }^{* * *} p<0.001$

residents to have a healthy lifestyle, which contradicts the lifestyle transition theory. In terms of SES, each SES group shows multidimensional lifestyles. As educational attainment increases, people lead healthier lifestyles. Compared to respondents with lower education levels, those who obtained vocational college or higher degrees are 3.495 times more likely to have a healthy lifestyle than to have a risky lifestyle, and they are 6.808 times more likely to have a healthy lifestyle than to have a mixed lifestyle. The corresponding advantages of high school graduates and middle school graduates over the risky lifestyle are $1.755\left(=\exp ^{0.562}\right)$ and $1.884\left(=\exp ^{0.634}\right)$, respectively. The two groups' advantages over the mixed lifestyle are $2.910\left(=\exp ^{1.068}\right)$ and $2.047\left(=\exp ^{0.716}\right)$, respectively. Respondents with lower educational attainment tend to have a mixed lifestyle-low probabilities of smoking and drinking, but also a lack of exercise and opportunities to rest and take physical exams. This is consistent with western research (Mirowsky and Ross, 1998). This finding supports the status constraint hypothesis. The present study also finds, however, a large percentage of highly educated Chinese lead risky lifestyles. In the mixed/risky comparison, the highly educated are more likely to have a risky lifestyle than the less educated. The highly educated are 1.948 times more $\left(=\exp ^{0.667}\right)$ likely to have a risky lifestyle than a mixed lifestyle. This finding contradicts western research, but it is consistent with Kim and colleagues' study. Therefore, the lifestyle transition hypothesis cannot be negated. What this reveals is, over the last 20 years, although the highly-educated Chinese have seen significant improvements in their lifestyles (their advantage towards healthy lifestyles has increased), and although 
they have moved towards a healthy lifestyle as in western countries, they have yet to overcome the tobacco and alcohol consumption modes in traditional Chinese culture. At the same time, their reliance on modern technology at work increases the likelihood of prolonged sitting, and work pressure reduces their chance to rest or relax. The relationship between occupational status and lifestyle is consistent with western research (Griep et al. 2015), supporting the status constraint hypothesis. Those with a highstatus occupation (professional/managerial employees) have advantages in autonomy at work, levels of control, working conditions and the resource distribution process, and they have higher standards for their lifestyles (such as smoking prohibitions at work). They therefore are more likely to have a healthy lifestyle. Specifically, compared to agricultural laborers, managerial/professional employees are 2.007 times more $\left(=\exp ^{0.697}\right)$ likely to have a healthy lifestyle than a risky lifestyle. Ordinary skilled workers and physical laborers also live more healthily than agricultural laborers. For ordinary skilled workers, the likelihood advantage to have a healthy lifestyle over a risky lifestyle is 1.953 times $\left(=\exp ^{0.670}\right)$ that of the agricultural workers, and for physical laborers and agricultural workers the ratio is $1.520\left(=\exp ^{0.419}\right)$. As most members of the two groups work in cities, their lifestyles are influenced and assimilated from urban residents. At the same time, because most of their employers have policies regarding physical exams built into the labor contract, they are more likely to take exams regularly than agricultural laborers. In contrast with the expectation from the status constraint hypothesis, staff members and individual businessmen/small business owners have no significant lifestyle difference from agricultural laborers, despite their much higher occupational status. This finding supports the lifestyle transition hypothesis. The influence of income on health-related lifestyles is similar to that of educational attainment, exhibiting a bipolar characteristic. Although it supports the status constraint hypothesis, it does not negate the lifestyle transition hypothesis. There is no significant difference in the probability of high-income people to have a healthy lifestyle versus a risky lifestyle, whereas low-income people tend to have a mixed lifestyle. Comparatively speaking, with every unit increase in the natural log of income, the likelihood advantage of having a healthy lifestyle over a mixed lifestyle increases by 1.232 times $\left(=\exp ^{0.208}\right)$, and that of having a risky lifestyle over a mixed lifestyle increases by 1.137 times $\left(=\exp ^{0.128}\right)$. On the one hand, according to the healthy lifestyle reproduction theory, high-income groups face lower economic pressure than low-income groups, and they are able to purchase health products. Their advantage in working conditions also raises their chance to take regular physical exams. In terms of group hierarchy, high-income groups are more likely to live in better neighborhoods (for example, commodity housing neighborhoods), which increases the possibility for them to live a healthy life. On the other hand, according to Kim and colleagues (Kim et al. 2014) and Wang and colleagues (Wang et al. 2008), higher-income groups in China consume more snacks and fried and processed foods, which are more expensive but less healthy.

\section{Generational differences in health-related behaviors and lifestyles}

From the above analysis, we can see that the SES-lifestyle correlation cannot be explained simply by either the status constraint hypothesis or the lifestyle transition hypothesis. In fact, because each social class is located at different positions in terms of 
education, occupation, and income, members of each SES group also differ in how they combine different health behaviors. At the same time, because the last style transition theory is an explanation based on social changes, it reflects changes in China's economic conditions before and after the Reform. Its influence on members of different SES groups is a time effect. Cross-sectional data is limited in testing changes such as a time effect. Therefore, this paper divides respondents into two birth cohorts-those born in or before 1977 and those born in or after 1978, and it applies the same models fit the whole sample to each cohort. It seeks to reflect lifestyle changes for different SES groups before and after the Reform. The results are shown in Table 5.

A preliminary comparison between the subsamples and the general sample reveals several things. First, the cohort born in or before 1977 is similar to the general sample in terms of estimated results for basic control variables such as gender and urban residency, as well as for SES variables such as education and income ${ }^{5}$. In this subsample, age does not have a significant influence on lifestyle. In terms of the occupational status variable, staff members and agricultural laborers differ significantly as to whether their lifestyles are healthy or risky (this difference is not significant in the general sample). Other occupational categories are similar to the general sample. In the cohort born in or after 1978, however, all major SES variables become insignificant, even though controlled variables such as gender, age, and urban residency are consistent with the general model in terms of the direction and significance of their coefficients. Moreover, the estimated coefficients for classes such as staff, ordinary skilled workers, and physical laborers turned negative (but insignificant). Generally speaking, if we only look at the comparison between healthy and risky lifestyles, people who were born in or before 1977 are more significantly influenced by SES variables. Their condition supports the status constraint hypothesis. In the population born in or after 1978, however, whether people have a healthy or risky lifestyle is mainly the result of demographic variables, while SES variables have almost no significant effects. The status constraint hypothesis is not supported here. Although we cannot infer from this that the lifestyle transition hypothesis is supported, it does reflect that for different generations, the pattern of influence by social economic status has changed. This point is emphasized by the lifestyle transition theory.

\section{Conclusion and discussion}

Although existing research in developed western countries has provided stable empirical support for the healthy lifestyle reproduction theory (Cockerham, 2010), the health-related behaviors of Chinese citizens challenge it. The reproduction theory has not provided sufficient explanation for this. Cholesterol transitions theory is built on the nutrition tradition theory (Popkin, 2003) that argues that Chinese people's lifestyles have changed in the process of social economic transition and are influenced by western societies. Members of the upper-class are most influenced by western lifestyles (Kim et al. 2004). This study proposes the status constraint hypothesis and the lifestyle transition hypothesis based on these two theoretical arguments. It tests these two competing theories based on the health-related lifestyles of Chinese citizens.

\footnotetext{
${ }^{5}$ As the models have different sample sizes and are not nested, this comparison is only about the direction and significance of the coefficients.
} 
Table 5 Multivariate logistic regression of the SES-lifestyle relationship for different birth cohorts

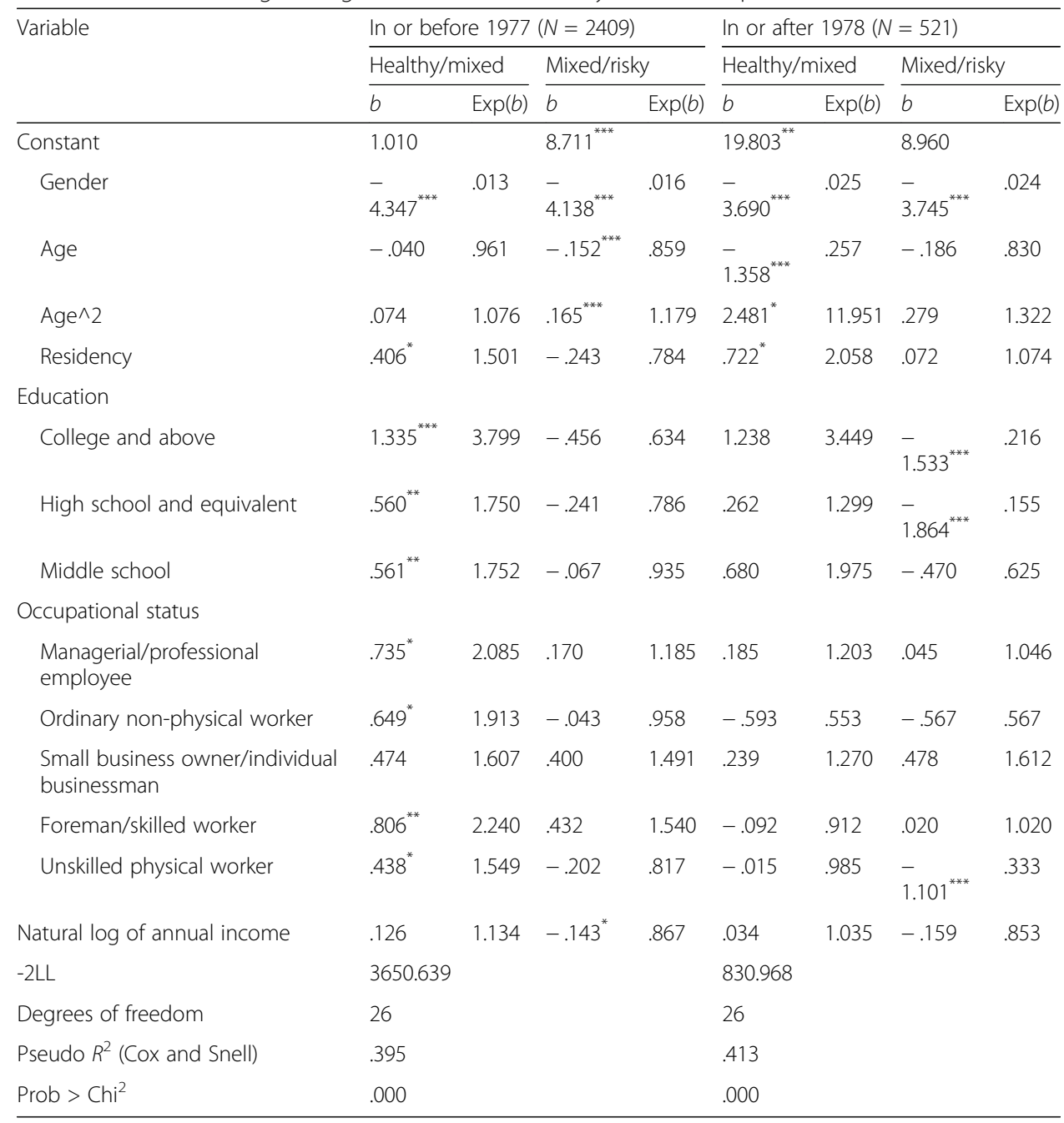

Note: ${ }^{*} p<0.05,{ }^{* *} p<0.01,{ }^{* * *} p<0.001$

Through a related cost analysis on the data from the Chinese General Social Survey (CGSS2010), this study divides people's lifestyles into three categories: mixed, healthy, and risky lifestyles. Each of them takes up 52.61\%, 27.68\%, and $19.71 \%$ of the sample, respectively. There is a considerable difference in how the five indicators combine over the three kinds of lifestyles. This means that at present, the lifestyles of Chinese people are multidimensional. Relatively few people have a healthy lifestyle, whereas the mixed and the risky lifestyles each take up a relatively large percentage.

In terms of the SES-lifestyle relationship, both the structural constraint hypothesis and the lifestyle transition hypothesis are partially supported (as shown in Fig. 1). Compared to low-education and low-income groups, highly educated and high-income groups are polarized in their lifestyles, with both the healthy and the risky lifestyles having considerable probability advantages. In other words, the healthy lifestyle has no significant advantage over the risky lifestyle. At the same time, people with lower educational attainment and lower income tend to have a mixed lifestyle. An analysis of occupational status gives support to the structural constraint hypothesis-people who have a higher occupational status are healthier than people who have a lower 


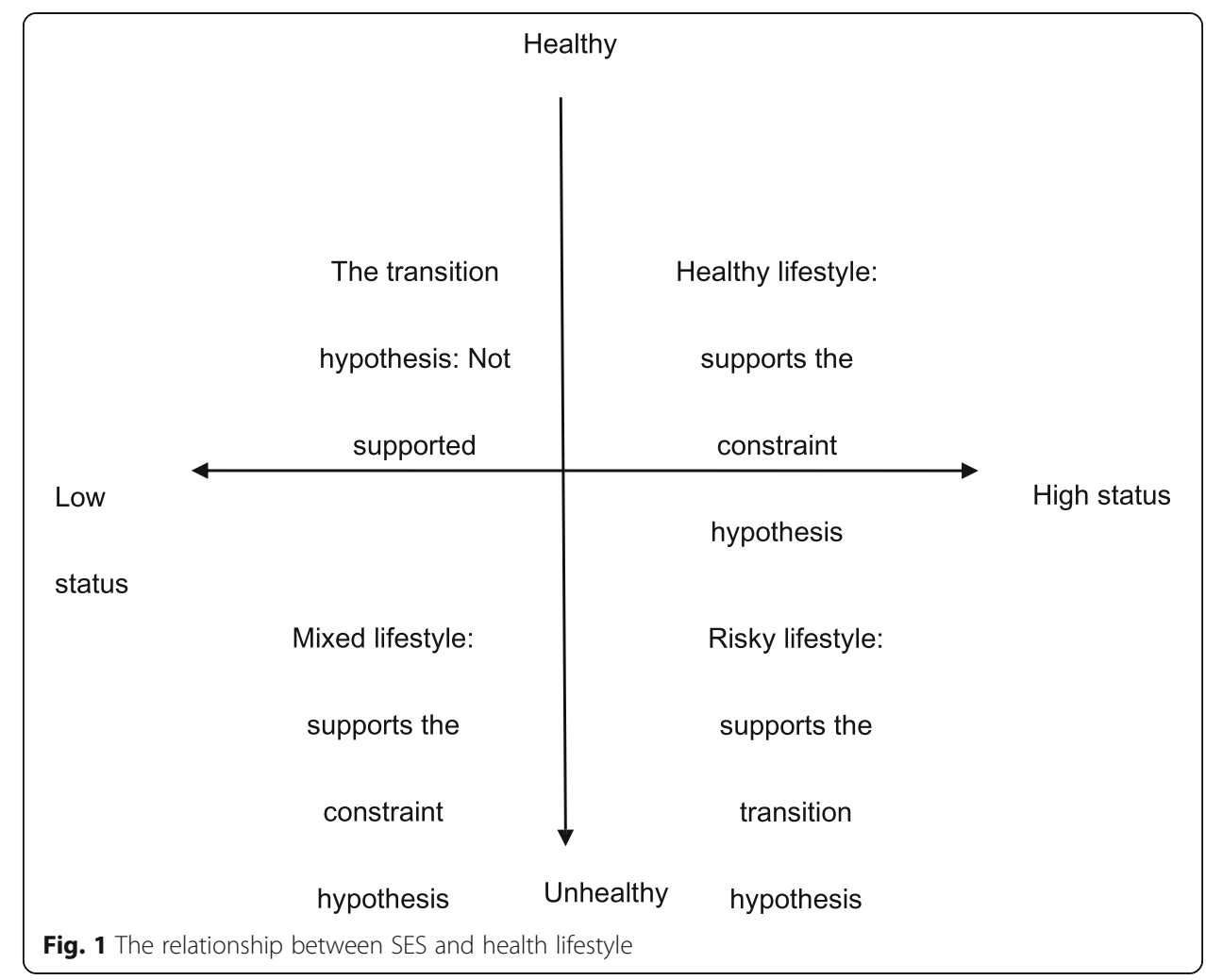

occupational status. Generally speaking, the healthy lifestyle of high-SES groups and the mixed lifestyle of low-SES groups can be explained by the logic of the healthy lifestyle reproduction theory. The former is located at the upper and middle of the social structure, control more social resources, and has advantages over those with low SES at both the individual and the structural levels. Therefore, they make better choices regarding health when facing certain opportunities. The risky lifestyle of high-SES groups can be explained by the logic of the lifestyle transition theory, as they are more influenced by western lifestyles. But the expectation of the transition hypothesis that people with lower SES are likely to have a healthy lifestyle is not supported, which means that lifestyle choices are still in the process of continuous transition. Moreover, by dividing the respondents into before-1978 and after-1978 birth cohorts and analyzing these subsamples, this study has found that the influence of SES variables on people's lifestyles has changed significantly. After the Reform, the effects of SES were generally insignificant, which indirectly supports the argument of the lifestyle transition hypothesis. Based on past research (Wang et al. 2008), the gradual transition from unhealthy to healthy lifestyles among members of the upper class reflects either their awareness of their own health condition or the success of national public health policies, health education and health intervention. The lifestyles of members of the lower class, however, have gradually changed from healthy to risky, revealing the increasingly limited opportunities faced by these people. The class differences in health-related lifestyles can cause increases in health-related inequality among Chinese citizens (Jiao, 2014).

In general, the relationship between SES and lifestyles in China is very complicated. We can observe the characteristics both of developed western countries and developing countries. It is not a simple linear relationship and cannot be illustrated by one simple 
health-related behavior. As citizens of a developing country, the Chinese people are both constrained by SES structure and influenced by the lifestyles of developed western countries. In research and political decision-making, we must consider the moderating effect of social economic development, as well as the effect of cultural differences on the relationship between SES and health-related lifestyles. Although this study managed to account for the correlations between different health behaviors with the latent class model, because of the lack of diet-related variables this study still lacks content validity for a health-related lifestyle latent variable. This should not be a reason for the insignificant influence of SES on health-related lifestyles for the birth cohort born in or after 1978. At the same time, because of the inherent limitations of the latent class model, such as certain probabilities of problematic categorization based on posterior probabilities, the conclusions of this study might be biased to some extent. Moreover, this paper cannot provide an explanation for the mechanism behind the lifestyle polarization of high-SES groups. These shortages should receive specific attention in future research.

Abbreviations

CGSS: Chinese General Social Survey; SES: socio-economic Status

Authors' contributions

The author read and approved the final manuscript.

\section{Funding}

This study is funded by the National Social Science Fund of China-Young Scholar Program "Research on protecting the rights of health of disadvantaged social groups from a social stratification perspective" (12CSH020).

\section{Availability of data and materials}

Anyone interested in this study can apply for the data (CGSS2010) sets used in this paper by contacting the Center for Survey and Statistics at Renmin University.

\section{Competing interests}

The author declares that he has no competing interests.

Received: 30 September 2019 Accepted: 9 December 2019

Published online: 30 December 2019

References

Abel, Thomas, William C. Cockerham, and Steffen Niemann. 2000. A critical approach to lifestyle and health. In Researching Health Promotion, ed. J. Watson and S. Platt, 54-77. New York: Routledge.

Biddle, Jeff E., and Daniel S. Hamermesh. 1990. Sleep and the allocation of time. Journal of Political Economy 1990 (5): 922-943.

Bourdieu, Pierre 1984. Distinction:A Social Critique of the Judgement of Taste. Cambridge: Harvard University Press,pp126-128.

Chan, C.W., and S.F. Leung. 2015. Lifestyle health behaviors of Hong Kong Chinese: results of a cluster analysis. Asia-Pacific Journal Of Public Health 2015 (3): 293-302.

China Alcoholic Drinks Association. 2015. Yearbook of the Chinese Alcohol Industry 2012-2013, 29-30. Beijing: China Light Industry Press.

Christensen, V.T., and R.M. Carpiano. 2014. Social Class Differences in Bmi among Danish Women: Applying Cockerham's Health Lifestyles Approach and Bourdieu's Theory of Lifestyle. Social Science \& Medicine 2014 (112): 12-21.

Cockerham, William C. 2010. Health lifestyles: bringing structure back. In The New Blackwell Companion to Medical Sociology, ed. W.C. Cockerham, 432-434. Willey: Blackwell.

Cockerham, William C 2014. Medical Sociology: Routledge,pp.45-47.

Cutler, D.M., and A. Lleras-Muney. 2010. Understanding differences in health behaviors by education. Journal of Health Economics 2010 (1): 1-28.

Ferrer, Rebecca A., and William Mp Klein. 2015. Risk perceptions and health behavior. Current Opinion in Psychology 2015 (91): 85-89.

Friestad, C and K. I. Klepp 2006. Socioeconomic status and health behaviour patterns through adolescence: results from a prospective cohort study in Norway. European Journal of Public Health 2006(1), pp. 41.

Gilbert, P.A., and S.E. Zemore. 2016. Discrimination and Drinking: A Systematic Review of the Evidence. Social Science \& Medicine 2016 (161): 178-194.

Griep, Rosane H, Aline A Nobre and Márcia Gm Alves.etc 2015. "Job Strain and Unhealthy Lifestyle: Results from the Baseline Cohort Study, Brazilian Longitudinal Study of Adult Health (Elsa-Brasil)." BMC Public Health 2015(1), pp. 1-10.

Jiao, Kaishan. 2014. Health inequalities of different socio-economic status and its influencing factors. Sociological Studies 2014 (5): $24-46$.

Kaljee, Linda, and X. Chen. 2011. Social capital and risk and protective behaviors: a global health perspective. Adolescent Health Medicine \& Therapeutics 2011 (2): 113-122. 
Kawachi, Ichiro, S. V. Subramanian and Daniel Kim 2008. Social Capital and Health: Springer New York,pp.289-290.

Kim, Soowon, Michael Symons, and Barry M. Popkin. 2004. Contrasting socioeconomic profiles related to healthier lifestyles in China and the United States. American Journal of Epidemiology 2004 (2): 184-191.

Li, Xia. 2012. The Change and Choice of Lifestyle, 52-53. Beijing: People's Publishing House

Lindström, Martin. 2008. Social capital and health-related behaviors. In Social Capital and Health, ed. I. Kawachi, S.V. Subramanian, and D. Kim, 215-238. Springer New York: New York, NY.

Liu, Jingming \& Lulu Li 2005, Becoming stratified: residential spaces, lifestyles, social networks and class identity: an empirical study of social stratums in urban China." Sociological Studies 2005 (3), pp. 52-81.

Mirowsky, John, and Catherine E. Ross. 1998. Education, personal control, lifestyle and health: a human capital hypothesis. Research on Aging 1998 (4): 415-449.

Mirowsky, John, and Catherine E. Ross. 2007. Life course trajectories of perceived control and their relationship to education. American Journal of Sociology 2007 (5): 1339-1382.

Morris, L.J., C. D'Este, K. Sargent-Cox, and K.J. Anstey. 2016. Concurrent lifestyle risk factors: clusters and determinants in an Australian sample. Preventive Medicine 2016 (84): 1-5.

National Health and Family Planning Commission. 2015. The China Health and Family Planning Statistical Yearbook (2015), 283-285. Beijing: Peking Union Medical College Press.

Pampel, F.C., P.M. Krueger, and J.T. Denney. 2010. Socioeconomic disparities in health behaviors. Annual Review of Sociology 2010 (1): 349-370.

Pearlin, L.I., and E.G. Menaghan. 1981. The Stress Process. Journal of Health and Social Behavior 1981 (4): 337-356.

Popkin, Barry M. 2003. The nutrition transition in the developing world. Development Policy Review 2003 (5): 581-597.

Powell, L. M., S. Slater, F. J. Chaloupka and D. Harper 2006. Availability of physical activity-related facilities and neighborhood demographic and socioeconomic characteristics: a National Study." American Journal of Public Health 2006(9), pp. 1676-1680.

Qiu, Haozheng. 2008. Latent Class Modeling: Principles and Techniques, 8. Beijing: Educational Science Publishing House.

Roshchina, Y. 2016. Health-related lifestyle: does social inequality matter? Journal Of Economic Sociology-Ekonomicheskaya Sotsiologiya 2016 (3): 13-36.

Skalamera, J and R. A. Hummer 2016. Educational attainment and the clustering of health-related behavior among U.S. young adults. Preventive Medicine 2016(84), pp. 83-89.

State Tobacco Monopoly Administration. 2013. Yearbook of Chinese Tobacco 2013, 457-458. Beijing: China Science Publishing. Wang, Fuqin. 2012. Socioeconomic status, lifestyle and health inequality. Chinese Journal of Sociology 32 (2): 125-143.

Wang, Z., F. Zhai, S. Du, and B. Popkin. 2008. Dynamic shifts in Chinese eating behaviors. Asia Pacific Journal of Clinical Nutrition 2008 (1): 123-130.

Weber, Max 1946, Economy and Society Volume I. Translated by Lin, Rongyuan. Beijing: Commercial Press, pp. 651-653.

WHO. 2005. Preventing Chronic Diseases: A Vital Investment, 190. Geneva.

Zhai, Feng Ying, Hui Jun Wang and Shu Fa Du .etc 2010. Prospective study on nutrition transition in China." Nutrition Reviews 2010(s1), pp. 56-61.

Zhao, M., Y Konishi and P Glewwe 2012. Does information on health status lead to a healthier lifestyle? Evidence from China on the Effect of Hypertension Diagnosis on Food Consumption." Journal of Health Economics 2012(2) , pp. 367-385.

Zhu, Di. 2013. Defending Taste: A path towards understanding modern Chinese consumers. Social Sciences in Guangdong 2013 (3): 206-212.

\section{Publisher's Note}

Springer Nature remains neutral with regard to jurisdictional claims in published maps and institutional affiliations.

\section{Submit your manuscript to a SpringerOpen ${ }^{0}$ journal and benefit from:}

- Convenient online submission

- Rigorous peer review

- Open access: articles freely available online

- High visibility within the field

- Retaining the copyright to your article

Submit your next manuscript at $\boldsymbol{\Delta}$ springeropen.com 